\title{
Universo consensual de adolescentes acerca da violência escolar
}

\author{
LidianeSilva deAraújo- UnivesidadeFedeal da Paraiba, JoãoPessaa, Paraíba, Brasil \\ Maria da Penha deLima Catinho- UnivesidadeFedeal da Paraíba, João Pessca, Paraíba, Brasil \\ RosanedeSasa Miranda - UnivesidadeFedaral da Paraiba, João Pessoa, Paraíba, Brasil \\ Evdyn Rúlia deAlbuquequeSaraiva - UnivesidadeFeekal da Paraíba, JoãoPessca, Paraíba, Brasil
}

\begin{abstract}
Resumo
Este estudo objetivou apreender as representações sociais da violência escolar elaboradas por adolescentes inseridos numa escola pública de João Pessoa, Paraíba. A amostra foi formada por 177 adolescentes dos sexos masculino e feminino, com idades entre 12 e 18 anos, os quais responderam a um questionário sociodemográfico e à associação livre de palavras, através dos estímulos "violência escolar" e "pessoa violentada". As evocações livres foram processadas no Tri-Dexx-Mas por meio da análise fatorial de correspondência. As representações sociais elaboradas pelos escolares apontaram para as manifestações características do fenômeno, assim como seus impactos para esse grupo social. Evidenciou-se, ainda, que a violência escolar apresenta-se como um fenômeno multifacetado, imbricado em outras formas de violência (física, psicológica e sexual). Com efeito, o estudo deste objeto social, para a amostra estudada, transpôs as barreiras da violência tipo bullying, apontando a sua realidade funesta para além desse termo.

Palavasdhave Violência escolar; Bullying Adolescência; Representações sociais; Tri-Dax-Mds
\end{abstract}

Consensual universe of adolescents about school violence

\begin{abstract}
This study aimed to understand the social representations of school violence produced by adolescents enrolled in a public school in Joao Pessoa, Paraiba. The sample consisted of 177 adolescents, male and female, aged between 12 and 18 years old, who completed a socio-demographic questionnaire and a word association test, through the stimulus "school violence" and "victim". The free evocations were processed by the Tri-Deux-Mots software, through correspondence factor analysis. Social representations elaborated by students have pointed to the characteristic manifestations of the phenomenon, as well as its impacts on this social group. It was also clear that school violence is presented as a multifaceted phenomenon, imbricated in other forms of violence (physical, psychological and sexual). Indeed, the study of this social object, for the sample studied, has crossed the barriers of violence, bullying, expanding his dismal reality to beyond the meaning of the word.
\end{abstract}

Kegwards School violence; Bullying; Adolescence; Social representations; Tri-D eux-Mots software.

\section{Universo consensual de adolescentes acerca de la violencia escolar}

\begin{abstract}
Resumen
Este estudio objetivó aprehender las representaciones sociales de la violencia escolar elaboradas por adolescentes de una escuela pública de Paraíba-Brasil. La muestra se compuso por 177 adolescentes de los sexos masculino y femenino, con edades entre 12 e 18 años, los cuales respondieron a un cuestionario sociodemográfico y la asociación libre de palabras, a través de los estímulos "violencia escolar" y "persona violentada". Las evocaciones libres fueron procesadas en el TriDexx-Mas por medio del análisis factorial de correspondencia. Las representaciones sociales elaboradas por los escolares apuntaron para las manifestaciones características del fenómeno, así como sus impactos para ese grupo social. Se evidenció, aún, que la violencia escolar se presenta como un fenómeno multifacético, imbricado en otras formas de violencia (física, psicológica y sexual). Con efecto, el estudio de este objeto social, para la muestra estudiada, transpuso las barreras de la violencia tipo bullying, señalando su realidad funesta para allá de este término.

Palabrasdave Violencia escolar; Bullying; Adolescencia; Representaciones sociales; Tri-D eux-Mots.
\end{abstract}

Nos últimos tempos, a sociedade tem assistido à elevada disseminação das diversas formas de violência. Apesar de afetar o tecido social no momento atual, a violência constitui um fenômeno universal, complexo e polissêmico que acompanha a humanidade desde o seu princípio, manifestando-se de forma enigmática e compreendendo, portanto, realidades bastante diferenciadas em decorrência dos contextos sociais, históricos, econômicos ou culturais específicos (Minayo, 2006).

A violência é um problema histórico, que tem suas raízes fincadas em macroestruturas, conferindolhe formas de expressão conjunturais, atualizando-se no cotidiano das relações interpessoais, sendo uma questão essencialmente social (Minayo, 2006; Santos \& Ferriani, 2007). Nesse aspecto, a O rganização Mundial de Saúde (OMS, 2002) afirma que a violência é uma constante na vida de um grande número de pessoas em todo 0 mundo, de todas as gerações, grupos sociais e culturais, denunciando sua presença desde os espaços públicos até os espaços privados, perpassando peloss locais de trabalho, o seio familiar, além das variadas instituições de convivência social, inclusive as escolas.

Quando imersa no âmbito escolar, torna-se perceptível a sua repercussão como um problema social grave e complexo e, provavelmente, como o tipo mais frequente e visível da violência juvenil; ela é assim chamada por ser cometida por pessoas com idades 
entre 10 e 21 anos (Lopes Neto, 2005). D essa forma, 0 tipo de violência que mais aflige crianças e adolescentes é aquela que se dá no plano interpessoal, particularmente no contexto familiar e escolar, sem necessariamente desconsiderar uma forma de violência mais ampla ou estrutural (Assis, Avanci, Santos, Malaquias \& Oliveira, 2004).

0 problema da violência escolar tem despertado 0 interesse crescente de pesquisas em âmbito mundial, tendo em vista os problemas cotidianos que são registrados nas escolas (Bringiotti, Krynveniuk \& Lasso, 2004). Embora constitua um problema antigo no contexto escolar, a partir das três últimas décadas do século $\mathrm{XX}$, a violência escolar galgou maior visibilidade nos veículos midiáticos, nas conversações do cotidiano, assim como no campo científico, sobretudo a partir dos estudos desenvolvidos por $\mathrm{D}$ an Olweus $(1978,2004)$, norueguês reconhecido por ser precursor nas pesquisas sobre o bullying (Antunes \& Zuin, 2008).

Desde então, as pesquisas sobre 0 tema percorreram quase todos os países, inclusive o Brasil, que passaram a estudar a problemática da violência escolar por meio da faceta designada bullying (Oliveira \& Gomes, 2012; Trautmann, 2008; Viding, McCrory, Blakemore \& Frederickson, 2011). Esse construto pode ser definido como um conjunto de comportamentos agressivos, físicos ou psicológicos que ocorre entre pares no contexto escolar, caracterizado pela persistência no tempo e passível de causar danos aos atores sociais envolvidos. Pode ainda ser qualificado por comportamentos típicos, tais como: chutar, empurrar, apelidar e excluir, que ocorrem entre colegas por repetidas vezes e sem motivação evidente, quando um grupo de alunos ou um aluno com mais força vitimiza outro, que não consegue encontrar um modo eficaz para se defender (Lopes Neto, 2005; Olweus, 2004; Smith, 2002).

Entre outras caracterizações do bullying Fante (2005) destaca os insultos, intimidações, atuação de grupos que hostilizam, ridicularizam e infernizam a vida de outros alunos, causando danos físicos, morais e materiais, mediante apelidos cruéis, gozações e acusações injustas. D entre as características pertinentes ao bullying os aspectos aludidos apresentam-se como principais, tanto em termos de ocorrência, como no nível das consequências àqueles envolvidos com 0 problema.

Segundo Lopes Neto (2005), é importante salientar os riscos que podem ser causados por esse fenômeno, ou seja, os possíveis impactos que podem afligir a saúde do escopo social e, sobretudo, a constituição desses adolescentes em desenvolvimento. Com base nessas considerações, verifica-se que 0 cenário atual das pesquisas realizadas tem enfatizado a violência escolar primordialmente a partir do fenômeno bullying em detrimento das demais facetas da violência que perfazem o universo escolar.

Nesta tela, reconhecendo os aspectos pertinentes à violência que atravessa a esfera escolar, sabe-se que 0 fenômeno pode significar problemáticas subjacentes à própria dinâmica escolar estabelecida entre os atores sociais desse contexto. Assim, ao reduzir o fenômeno da violência na escola, como bullying os teóricos podem mascarar questões muito complexas, tais como a problemática das drogas, além de outras formas de violência relacionadas ao preconceito, assédio, exclusão, discriminação e a desigualdade social, naturalizando, por vezes, tais questões e dificultando suas elucidações (Antunes \& Zuin, 2008; Sawaia, 2006).

Nesse contexto, embora haja um considerável aumento de estudos sobre o construto, verifica-se que muitos apreendem o fenômeno por um prisma ainda prioritariamente psicológico e individualizado, enfocando o problema a partir da relação entre vítima e agressor (ver perspectivas: Fante, 2005; Silva, 2010). Nesta conjuntura, por reconhecer as lacunas ainda existentes nesse campo de investigação, o presente trabalho circunscreve-se sob o olhar psicossociológico, fundamentado na abordagem dimensional da Teoria das Representações Sociais (Jodelet, 2001; Moscovici, 2009), tendo como propósito a compreensão da dialética que compõe 0 discurso forjado pelos adolescentes em face do seu entorno social, especificamente, do seu universo de pertença grupal.

As representações sociais podem ser concebidas como processos nutridos não só pelas teorias científicas, mas também pelos importantes eixos culturais, suas ideologias, as vivências e comunicações travadas no decurso do cotidiano. Segundo definição clássica proposta por Jodelet (1989), a representação social significa uma "modalidade de conhecimento, socialmente elaborada e partilhada, com um objetivo prático e contribuindo para a construção de uma realidade comum a um conjunto social” (Jodelet, 1989, p. 36).

Nesta pesquisa, o estudo da violência escolar à luz do aporte teórico-metodológico das representações sociais se justifica pelos critérios de espessura cultural e relevância social que preenchem 0 objeto de investigação (Sá, 1998). Tais características, por conseguinte, permitem vislumbrar 0 universo consensual dos próprios atores sociais (adolescentes escolares) acerca das vivências imbricadas nas manifestações da violência no cotidiano desses alunos.

Nesta tela, adotou-se, como meta principal para a presente investigação, apreender as representações sociais dos adolescentes acerca da violência escolar. 
Procurou-se, ainda, delinear o perfil dos participantes quanto às variáveis sociodemográficas, como também assinalar similitudes e diferenças das representações sociais expressas nas evocações dos adolescentes escolares, apreciando a idade, o sexo, o relacionamento com os pares e o sentimento de segurança na instituição de ensino. Assim, espera-se que os achados provenientes deste estudo possam subsidiar a formulação e/ ou reformulação de políticas públicas voltadas à promoção de saúde, bem como à intervenção eficaz do problema da violência no contexto escolar.

\section{Participantes}

\section{Método}

A amostra foi do tipo não-probabilística (de conveniência). Participaram desta pesquisa 177 adolescentes de uma escola pública da cidade de João Pessoa, Paraíba, com idade média de 14,43 anos ( $\mathrm{DP}=1,87$; amplitude de 12 a 18 aos), a maioria do sexo feminino $(51 \%)$.

\section{Instrumentos}

Foram utilizados como instrumentos 0 Questionário Sociodemográfico e a Técnica de Associação Livre de Palavras (TALP). Estes serão descritos a seguir.

\section{Questionánio Sociodamogáfico}

Foi utilizado com a intenção de obter um perfil característico da amostra, além de alcançar informações necessárias para a composição das variáveis fixas utilizadas para 0 banco de dados processado pelo programa computacional Tn-Dex-Mats Tais variáveis compreenderam questões sobre sexo, relacionamento com os pares, sentimento de segurança na escola e gostar ou não da instituição.

\section{Témica deAssciacãoLivredePalavas(TALP)}

Esta técnica foi utilizada por meio dos estímulos indutores 1) "violência escolar" e 2) "pessoa violentada". Esses estímulos foram assim empregados com o desígnio de articulá-los com o objeto social da presente investigação, conforme recomendam Nóbrega e Coutinho (2003). O propósito de usar a técnica consistiu em identificar as dimensões latentes das representações por meio da configuração dos elementos que constituem as redes associativas dos conteúdos evocados em reação a cada estímulo ou palavra indutora. Assim, para a proposta deste estudo, a técnica mostrou-se pertinente, pois facilitou a "atualização de elementos implícitos ou latentes que seriam perdidos ou mascarados nas produções discursivas" (Abric, 1994, p. 66).

\section{Procedimento}

A pesquisa foi desenvolvida após aprovação do projeto pelo Comitê de Ética em Pesquisa com Seres Humanos, do Hospital Universitário Lauro Wanderley - UFPB, levando em consideração a Resolução 196/ 96 (Brasil, 1996). Desse modo, medidas foram tomadas para resguardar os direitos dos adolescentes escolares e deixá-los à vontade para responder à pesquisa. Além disso, foram esclarecidos aos participantes os objetivos do estudo, bem como foram garantidos o anonimato e o sigilo das informações dos mesmos, assegurando-lhes a possibilidade de desistência à colaboração a qualquer momento do estudo.

Realizou-se contato prévio com a direção da instituição escolar com o intento de conferir a autorização dos responsáveis pelos alunos para 0 procedimento de coleta de dados. A seguir, e com a disponibilidade dos estudantes para a participação voluntária nesta pesquisa, foram explicitados os objetivos pertinentes ao estudo, além de garantido 0 anonimato e confidencialidade das respostas proferidas pelos participantes, uma vez que os dados foram tratados em seu conjunto.

Quanto à aplicação dos instrumentos, esta se deu de forma coletiva, nas próprias dependências da escola pesquisada, sob a responsabilidade das pesquisadoras devidamente treinadas, que entregaram aos alunos um livreto com 0 conjunto de instrumentos. Para a aplicação da TALP, seguiram-se as orientações de Nóbrega e Coutinho (2003), que sugerem uma simulação prévia com os participantes para deixá-los familiarizados com a técnica e, em seguida, pronunciar as instruções sobre o instrumento que, a propósito, consistem em pedir para 0 participante falar as primeiras palavras ou expressões que surgem à mente após ouvir os estímulos indutores escolhidos para a pesquisa (Saraiva, 2007).

\section{Análisedos dados}

Após a coleta dos dados, as respostas referentes ao questionário sociodemográfico e à técnica de associação livre de palavras foram processadas pelo softuare Tri-Dex-Mds (Cibois, 1995) e analisadas por meio da análise fatorial de correspondência (AFC). Este tipo de análise foi adotado com a finalidade de compreender o destaque dos eixos que explicam as modalidades de respostas dos participantes do estudo, mostrando "estruturas constituídas de elementos do campo representacional ou gráfico" (Coutinho, 2005, p. 167) e facilitando o estudo dimensional das representações sociais. 


\section{Resultados e discussão}

Apresentar-se-ão, a seguir, os resultados alcançados por meio da aplicação do questionário sociodemográfico e da técnica de associação livre de palavras, com o intuito de utilizá-los como ferramentas para 0 acesso à investigação das representações sociais da violência escolar e pessoa violentada, formadas pelos adolescentes escolares desta pesquisa. Neste aspecto, serão ilustradas as características da amostra e, logo em seguida, serão explicitadas as evocações livres dos participantes em face dos estímulos indutores, processadas por meio do programa computacional TriDax-Mds

Considerando a amostra pesquisada, realizou-se um cálculo de frequências e percentagens das respostas dos participantes a alguns itens do questionário sociodemográfico que avaliavam a dinâmica da relação entre os escolares e o seu contexto de pertença grupal, dentre os quais as seguintes perguntas: (i) "como você se relaciona com seus colegas da escola?", com a escala de resposta: bem razóád ou mal; (ii) "você gosta desta escola?" e (iii) "você se sente seguro nesta escola?, ambas com escala de avaliação dicotômica (sim/ não)" .

Com base na análise dos dados, foi possível identificar os seguintes percentuais de respostas dos adolescentes: $57,8 \%$ dos alunos reportaram não se sentirem seguros na escola. A maioria deles indicou ter um bom relacionamento com os pares, perfazendo um percentual de $64,6 \%$. A maioria dos estudantes disse gostar da escola onde estuda, ao passo que $27,2 \%$ afirmou não gostar da instituição.

Com o propósito de apreender as representações sociais dos adolescentes acerca do objeto de interesse, os dados advindos da associação livre de palavras foram processados no programa computacional TriDeax-Mds 0 referido programa foi utilizado com 0 desígnio de representar graficamente a aproximação e 0 distanciamento entre as variáveis fixas e as variáveis de opinião apresentadas pelos adolescentes desta pesquisa. Tais variáveis foram constituídas tendo em vista 0 questionário sociodemográfico e as evocações dos adolescentes ante os estímulos indutores na associação livre.

A codificação dessas variáveis estruturou-se a partir das variáveis de opinião (evocações diante dos estímulos "violência escolar" e "pessoa violentada") e das variáveis fixas. Estas explicitavam algumas características dos participantes já evidenciadas no questionário sociodemográfico, tais como idade, sexo, indicativo do relacionamento com os colegas escolares e o sentimento de segurança nesse espaço.

O processamento dos dados pelo satwarepermitiu a Análise Fatorial de Correspondência das evocações dos adolescentes ante os estímulos indutores com as maiores cargas fatoriais coligadas às variáveis sociodemográficas já mencionadas. D esse modo, foram registradas 1509 palavras inscritas como respostas dos participantes aos estímulos; destas, 454 foram palavras diferentes, como resultado da junção dos termos com similaridade semântica executada pelo programa. No conjunto dessas palavras, 89 envolveram 0 plano fatorial de correspondência, de acordo com a distribuição relativa de cada palavra para o espaço fatorial.

As palavras referenciadas compreenderam carga fatorial média igual a 11,24, adotando-se por fundamento o somatório das cargas (1000) dividido pelo número total de palavras (89). Nesta tela, para acessar as representações sociais acerca do objeto de investigação de interesse, no transcurso da análise dos dados, optou-se por adotar o dobro da média das cargas fatoriais (11,24 x 2), isto é, 22,48, para destacar as palavras que apresentaram contribuições mais significativas na constituição dos fatores no gráfico. Pela análise das contribuições para cada estímulo indutor, verificaram-se alguns destaques característicos dos discursos dos alunos.

Para os adolescentes, a violência escolar foi representada como sinônimo de assédio visto como um dos fatores desestruturantes das relações estabelecidas na escla Segundo os alunos, o fenômeno pode se apresentar mediante diversas ações, dentre as quais: rabar, matar, machucar, brigar, dar mmos, xingar e falar palavãa Nesse sentido, a violência escolar pode ser vista como uma bagnga que afeta a vida do alunoe que é sustentada pelo abuso de poder, pela falta de educaçãoe de respito para com o outro, sendo elemento crucial para a manutenção das relações pautadas nos sentimentos de ódo dore lamento (dhoro).

As palavras com maiores cargas fatoriais (isto é, superiores a 22,48) associadas ao estímulo indutor "pessoa violentada" apontaram que a base do universo consensual dos alunos caracterizou a pessoa violentada como vítima dos impactos causados pela vidênia(brigar, matar, raubo, tapa) - um fenômeno que pode traumatizar e machurar a vítima, provocando um sofimento exacerbado, sinais de depressãa angústia e tristeza, gerando medbe insegurança ou provocando a motecomo realidade próxima. Seguindo o modelo interpretativo proposto por Saraiva (2007), as discussões acerca do universo consensual dos adolescentes sobre a violência escolar serão apresentadas no conjunto da análise e dos comentários sobre o plano fatorial de correspondência decorrente da análise efetuada no saftware Tri-DexMoss de acordo com a Figura 1. 


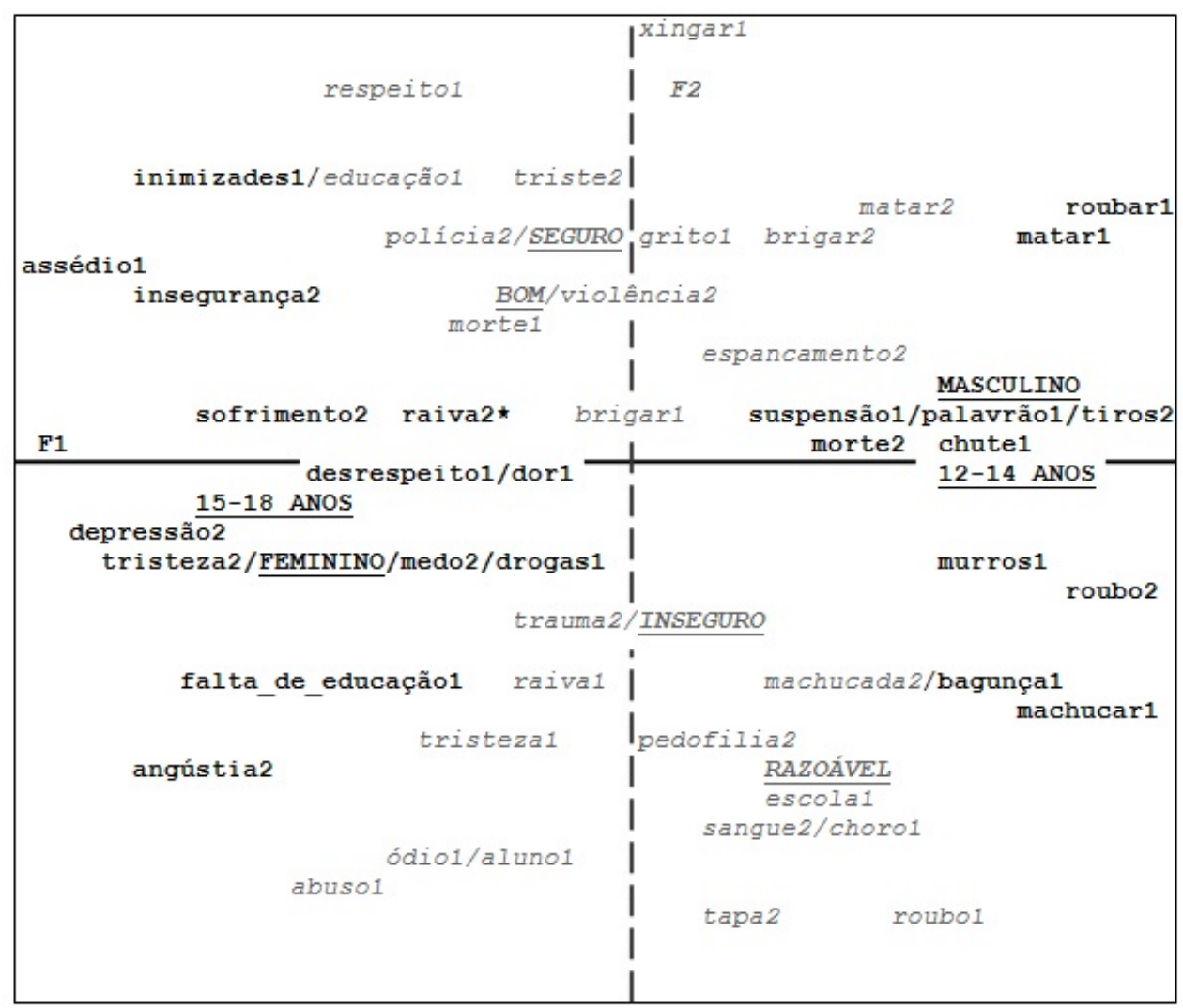

Figura 1. Plano fatorial de correspondência das representações sociais forjadas pelos adolescentes escolares

A Figura 1 apresenta 0 plano fatorial de correspondência das representações sociais elaboradas pelos adolescentes da pesquisa, que foi construído a partir da leitura das modalidades, palavras evocadas ou campos semânticos, distribuídas de maneira antagônica sobre os dois eixos ou fatores (fator 1 e fator 2) do gráfico que, juntos, explicaram $69,5 \%$ da variância total das respostas e evidenciaram a análise das variáveis ou modalidades que tiveram contribuição superior a duas vezes a média das cargas fatoriais identificadas pelo softuare

0 primeiro fator (F1), destacado em negrito na linha horizontal, expôs as maiores cargas fatoriais, explicando $38 \%$ da variância total de respostas dos adolescentes. Nesse eixo, a direção negativa do gráfico revela as variáveis de opinião explicitadas pelas adolescentes do sexo feminino, na faixa etária de 15 a 18 anos. Para esse grupo, a violência escolar é sinônimo de assédio destespeito e falta de exuraçãa que pode desencadear para a escola uma atmosfera de dore inimizades para e entre os atores sociais. Além dessas evocações, a violência escolar também foi objetivada como fenômeno atravessado pelas drogas

Desse modo, reconhece-se que a ancoragem da violência escolar foi influenciada pela construção dos papéis de gênero que se estabelecem na sociedade. Além disso, tal representação foi atravessada pela ideologia do controle social, que tira a violência da esfera estrutural e a coloca na esfera interpessoal, como processo responsável pelos alunos e, para tanto, deve ser combatido através do respeito e educação (Albino \& Terêncio, 2010; Ferrari, 2010), desembocando num processo de individualização da violência social.

Em oposição, no mesmo fator, identificaram-se as evocações dos adolescentes do sexo masculino, com idades entre 12 e 14 anos. Esse grupo de pertença objetivou a violência escolar pelas ações de rabar, matar, dutar, falar palavão e bater, que transformam 0 espaço educativo numa bagunça, podendo levar seus transgressores à suspensãa

Não obstante 0 distanciamento dos conteúdos representacionais formados por esse grupo e o grupo das meninas, verifica-se uma aproximação desses dois discursos, em face do seu processo de construção na sociedade. Com efeito, aos meninos e meninas, a sociedade designa papéis diferenciados, 0 que corrobora posicionamentos ideológicos e práticos diferenciados aos dois grupos, influenciando, por conseguinte, na construção das representações sociais, que têm implicação prática na orientação da comunicação e do comportamento desses adolescentes (Coutinho, Silva \& Araújo, 2009; Ferrari, 2010; Jodelet, 1989, 2001).

No fator destacado em itálico (F2), na linha vertical do plano, com um percentual de 31,5\% da variância total de respostas, evidenciam-se dois campos 
semânticos distintos. O primeiro, apresentado no campo superior do gráfico, identifica as evocações dos participantes que afirmaram ter segurança na escola, assim como um bom relacionamento com os colegas. Nesse grupo, os alunos "seguros" e que apresentam "bom" relacionamento social evocaram a violência escolar como sinônimo de falta de respeitoe de eduracãa podendo ser objetivada como xingamento brigas ou mote

Distintamente, no plano inferior, identificam-se as livres associações do grupo de adolescentes que disseram ter um relacionamento razoável com os pares e, ainda, que reportaram sentimentos de insegurança quanto ao espaço escolar. Para esses adolescentes, a violência foi caracterizada como fenômeno realizado eminentemente pelo alumo no cenário esclar, configurando-se como sinônimo de rabo e abusa que suscita raiva, tristera ódoe doro

Segundo Ramírez, Quintero, Aguilar e Méndez (2007), os aspectos afetivos destacados pelos adolescentes possivelmente são decorrentes do clima social que configura a escola onde são permeadas práticas de abuso contra e entre os estudantes, podendo desenvolver nos alunos sentimentos de injustiça, tristeza e rancor. D iante das interlocuções dos participantes, infere-se 0 quadro de impactos psicossociais desencadeados pela violência na esfera escolar (Coutinho \& cols., 2009).

Quanto ao estímulo "pessoa violentada", os adolescentes ancoraram o objeto de investigação nas modalidades de violências física, sexual e psicológica, destacando as suas manifestações e impactos. Diante do estímulo em questão, os escolares objetivaram-no através de seus efeitos à pessoa violentada, provocando insegurança, sofimento depressãa medo angústia, traumas tristeza e, em alguns casos, a associação do fenômeno à mote Tais evocações emergiram como impactos sofridos pela pessoa violentada quando exposta a manifestações de violência descritas como epancamento tiros raba brigase peebfilia.

Os resultados indicam que a violência escolar se configura como um fenômeno multifacetado, perpassado por outras formas de violência presentes no tecido social, recebendo assim um caráter pluridimensional e multicausal (Agudelo, 1990; Minayo, 2006). Nesta tela, faz-se mister um olhar prioritário do Estado para a (re)formulação de políticas públicas eficazes para a prevenção e enfrentamento do fenômeno nos âmbitos da educação e da saúde pública.

\section{Considerações finais}

O presente estudo teve como objetivo identificar as representações sociais de adolescentes sobre a "violência escolar". Nesta pesquisa, foi possível acessar 0 universo consensual de adolescentes da capital paraibana acerca do objeto de investigação em questão, o que permitiu a apreciação científica do conhecimento do senso comum forjado pelos adolescentes escolares no seu contexto de pertença grupal.

0 desenho metodológico utilizado possibilitou a compreensão sobre o objeto de estudo à luz dos próprios atores sociais em sua interface com as vivências relacionadas às possíveis manifestações de violência no cotidiano. Com isso, destacou-se a importância da Teoria das Representações Sociais (Moscovici, 2009) para a investigação da violência escolar pela identificação dos conteúdos representacionais explanados pelos adolescentes, que foi favorecido pela abordagem dimensional conduzida por Jodelet (2001).

A partir desses achados, evidenciou-se que 0 conhecimento partilhado pelos escolares apresentou algumas similitudes e diferenciações. Quanto aos afastamentos entre os discursos dos participantes, pôde-se ratificar essa situação mediante a natureza dos conteúdos evocados, que demonstraram características peculiares em relação a determinados grupos de pertença. Nesse caso, nomeadamente, verificaram-se que as evocações dos meninos e meninas foram diferentes em termos comportamentais. Por outro lado, em geral, as ancoragens relacionadas à formação dessas representações admitiram uma consensualidade não do ponto de vista dos conteúdos, mas de uma mesma ascendência ideológica: a construção dos papéis de gênero que se dão no arcabouço social; além do reconhecimento das diversas formas de violência que atravessam a sociedade e, ao mesmo tempo, o fenômeno da individualização da violência escolar.

Apesar dessas descobertas, sugere-se a realização de estudos futuros que possam averiguar uma comparação entre estes dois objetos de investigação: a vidêna solar e uma de suas facetas, 0 bullying Portanto, para pesquisas futuras, propõe-se a utilização deste último termo como um dos estímulos indutores que favoreça a apreensão das representações sociais dos adolescentes à luz da abordagem dimensional.

Além dessas indicações, recomenda-se para pesquisa posterior a adoção de outras estratégias metodológicas associadas à utilização de abordagens teóricas complementares à matriz das representações sociais, tais como a abordagem estrutural (Abric, 1994; Flament, 2001) e a abordagem societal (D oise, 2002), com 0 intuito de aprofundar o estudo do referido construto na perspectiva das representações sociais.

Salienta-se, ainda, que as reflexões teóricas e críticas travadas no decurso deste trabalho foram corroboradas pelo conhecimento do senso comum, 
que apontou para a violência escolar como fenômeno díspar do bullying (Antunes \& Zuin, 2008; Ferrari, 2010). Com isso, o fenômeno transpôs a configuração da violência como acontecimento essencialmente de intimidação que ocorre entre os pares, evidenciando a sua realidade funesta para além deste termo primordialmente psicológico.

Em síntese, os resultados encontrados neste estudo destacaram a violência escolar como um fenômeno atravessado por outras formas de violência presentes no tecido social, recebendo, assim, um caráter endêmico e pluridimensional, que acarreta fortes impactos ao tecido social (Coutinho \& cols., 2009; Minayo, 2006). Por esse motivo, urge do Estado atenção prioritária para a prevenção e enfrentamento do fenômeno.

Com os resultados advindos do presente estudo, espera-se contribuir para a compreensão da violência escolar no contexto estudado. Isto é, confia-se que a análise das dimensões das representações sociais formadas pelos adolescentes escolares possa direcionar a elaboração de programas de prevenção do fenômeno, o que será viabilizado pelo retorno à instituição pesquisada, com o intuito de discutir os achados e efetivar as propostas de intervenção sobre a violência escolar.

\section{Referências}

Abric, J. C. (1994). Pratiques soiales \& représentations Paris: Presses Universitaires de France.

Agudelo, S. F. (1990). La violencia: un problema de salud publica que se agrava en la región. Bdein Epidamidog்odela OPS, 11, 01-07.

Albino, P. L., \& Terêncio, M. G. (2010). Considaraçês áticas sdbre o fenômenonobullying do concitoaocombate eà preençãa Em: Âmbito Jurídico, Rio Grande, 76. Recuperado: 28, maio, 2010. Disponível: http:/ / portal.pmf.sc.gov.br/ arquivos/ arquivos/ p df/ 18032010 15.21.10.2af5ca0c78153b8b4a479 93d66а̄51436.p $\overline{\mathrm{df}}$.

Antunes, D. C., \& Zuin, A. A. S. (2008). D o bullying ao preconceito: os desafios da barbárie à educação. Psicoloja eScciedade, 20(1), 33-41.

Assis, S. G., Avanci, J. Q., Santos, N. C., Malaquias, J. V., \& Oliveira, R. V. C. (2004). Violência e representação social na adolescência no Brasil. Revista Panamericana deSaludPublica, 16(1), 43-51.

Brasil. (1996). Ministéioda Saúde Conselho Nacional de Saúde. Resdução no 196, de 10/10/ 1996. Disponível: http:/ / conselho.saude.gov.br/ resolucoes/ 1996/ R eso196.doc.

Bringiotti, M. I., Krynveniuk, M., \& Lasso, S. (2004). Las multiples violencias de la "violencia" en la escuela: desarrollo de un enfoque teorico y metodologico integrativo. Paidêa, Riberão Preto, 14(29), 313-325.

Cibois, U. F. R. (1995). Tri-dax-mots Versão 2.2 Paris: Sciences Sociales.

Coutinho, M. P. L. (2005). Depressão infantil: uma abardagem psicosscial. João Pessoa: Ed. Universitária.

Coutinho, M. P. L., Silva, C. M. L., \& Araújo, L. S. (2009). O adolescente e o bullying no contexto escolar: um estudo psicossociológico. Em: IV Conferênia Brasileira sobre Representaçós Sociais A Escda Brasilera de Representaçós Sociais Rio de Janeiro: UERJ.

Doise, W. (2002). Da psicologia social à psicologia societal. Psicdoga: Temia ePequisa, 18(1), 27-35.

Fante, C. (2005). Fenômenobullying Campinas: Verus.

Ferrari, A. (2010). "Eles me chamam de feia, macaca, chata e gorda. Eu fico muito triste" - Classe, raça e gênero em narrativas de violência na escola. Instrumeto- Revista deEstudbePesquisa emEducação, 12(1), 21-30.

Flament, C. (2001). Estrutura e dinâmica das representações sociais. Em D. Jodelet (O rg.), As representaçoes sodais (pp. 173-186). Rio de Janeiro: UERJ.

Jodelet, D. (1989). Répresentation sociales: um domaine en expansive. Em D. Jodelet (Org.), Les Repreatations Sociales (pp. 31-61). Paris: Puf.

Jodelet, D. (2001). As repreantaçâes sciais Rio de Janeiro: EdUERJ.

Lopes Neto, A. A. (2005). Bullying: comportamento agressivo entre estudantes. Jomal dePeøiatria, 81(5), supl., 164-172.

Minayo, M. C. S. (2006). Vidênia e saúde Rio de Janeiro: Fiocruz.

Moscovici, S. (2009). Representaçoes sodais inveticaç̃es em psicdoga social. Petrópolis: Vozes.

Nóbrega, S. M., \& Coutinho, M. P. L. (2003). O Teste de Associação Livre de Palavras. Em M. P. L. Coutinho \& cols. (O rgs.), Representaçaes Sociais abordagem interdisaiplinar (pp. 67-77). João PessoaPB: Ed. Universitária UFPB. 
Oliveira, J. R., \& Gomes, M. A. (2012). Bullying: reflexões sobre a violência no contexto escolar. Reista Educaç̃opor Escrito- PUCRS, 2(2), 2-14.

Olweus, D. (1978). Agression in the schools bullies and whippingboys Washington: Hemisphere.

Olweus, D. (2004). Bullying en la escuela: datos e intervención. III Reunoón Intemacional Sobre Bidoǵa Y Socidoǵa deLa Videnia. Centro Reina Sofia para el Estudio de la Violência.

OMS - Organização Mundial de Saúde. Informemundal sobrela videnia ela salud. Orcanizacón Panamericana dela Salud para la Organización Mundal dela Salud Washington, D. C, 2002. Recuperado: 3, junho, 2010.

Disponível: http:/ / www.who.int/ violence injury prevention/ violence/ world_report/ en/summary_es.pdf

Ramírez, L. Y. Á., Quintero, A. P. C., Aguilar, P. E., \& Méndez (2007). Actitudes hacia la violencia social entre iguales y su relación con variables sociodemograficas en tres grupos de estudiantes de secundaria de la ciudad de Bucaramanga. Revista Codombiama dePsicoóa, 16, 127-137.

Sá, C. (1998). A construção do djeto de pesquisa em representaçás soiais Rio de Janeiro: EdUERJ.

Santos, L. E. S., \& Ferriani, M. G. C. (2007). A violência familiar no mundo da criança de creche e pré-escola. Reista Brasilera de Enfemagem 60(5), 524-529.
Saraiva, E. R. A. (2007). A experiênia matema meeliada pala depressão pósparta um etudb das representacães soiais (Dissertação de Mestrado). Universidade Federal da Paraíba, João Pessoa, Brasil.

Sawaia, B. (O rg.). (2006). As artimanhas da exdusãa análise psicosscial e ética da desigualdade social. Petrópolis: Vozes.

Silva, A. B. B. (2010). Bullying - mentes perigosas nas esclas Rio de Janeiro: Fontanar.

Smith, P. K. (2002). Intimidação por colegas e maneiras de evitá-la. Em E. Debarbieux \& C. Blaya (O rgs.), Vidênia nas ecclas epdíticas públicas Pdíticas públicas(pp. 175-205). Brasília: UNESCO.

Trautmann, A. M. (2008). Maltrato entre pares: 0 "bullying". Una visión actual. Revista Chilena de Peeliatnáa, 79(1), 13-20.

Viding, E., McCrory, E., Blakemore, S. J., \& Frederickson, N. (2011). Behavioural problems and bullying at school: can cognitive neuroscience shed new light on an old problem? Trends in CognitiveSaienes, 15(7), 289-291.

Reedidoem06/ 09/ 2011

Reformuladbem31/ 05/ 2012

Aprovado em11/ 06/ 2012 
Sobre os autores:

Lidiane Silva de Araújo é mestranda pelo Programa de Pós-Graduação em Psicologia Social da Universidade Federal da Paraíba. Possui Formação (2011) e Licenciatura (2009) em Psicologia pela mesma instituição, onde atua como colaboradora do Núcleo de Pesquisa: Aspectos Psicossociais de Prevenção e Saúde Coletiva.

Maria da Penha de Lima Coutinho é professora do Departamento de Psicologia da Universidade Federal da Paraíba. Coordenadora do Núcleo de Pesquisa: Aspectos Psicossociais de Prevenção e Saúde Coletiva. Possui doutorado em Psicologia Clínica pela Universidade de São Paulo (2001), mestrado em Psicologia da Saúde pela Universidade Federal da Paraíba (1986) e graduação em Psicologia pela mesma instituição (1978).

Rosane de Sousa Miranda é doutoranda pelo Programa de Pós-Graduação de Psicologia Social da Universidade Federal da Paraíba, onde faz parte do Núcleo de Pesquisa Aspectos Psicossociais de Prevenção e da Saúde Coletiva. Possui Mestrado em Psicologia Social pela Universidade Federal da Paraíba (2011) e Graduação em Psicologia pela Universidade Federal do Maranhão (2007).

Evelyn Rúbia de Albuquerque Saraiva é doutora e Mestre em Psicologia (Psicologia Social) pela Universidade Federal da Paraíba (UFPB), graduação em Psicologia Formação de Psicólogo pela Faculdade de Filosofia do Recife (1975), graduação em Psicologia Licenciatura pela Faculdade de Filosofia do Recife (1975). Atualmente é professor associado I da UFPB.

Contato com os autores:

Rua Bacharel Wilson Flávio Moreira Coutinho, 910, Condomínio Residencial Vale do Sul, casa 113 - CEP 58052510. Bairro Jardim Cidade Universitária. João Pessoa - PB, Brasil.

E-mail: lidianearaujojp@gmail.com 